\title{
Polypharmacy in older patients: identifying the need for support by a community pharmacist
}

\author{
Jean-Baptiste Beuscart ${ }^{1,2^{*}} \mathbb{D}$, Ségolène Petit ${ }^{3}$, Sophie Gautier ${ }^{4}$, Patrick Wierre ${ }^{5}$, Thibaut Balcaen ${ }^{1,6}$, \\ Jean-Marc Lefebvre ${ }^{7}$, Nicolas Kambia ${ }^{8}$, Elisabeth Bertoux ${ }^{5}$, Daniel Mascaut ${ }^{5}$, Christine Barthélémy ${ }^{8}$, Damien Cuny ${ }^{9}$, \\ François Puisieux ${ }^{1,2}$ and Bertrand Décaudin ${ }^{3,8}$
}

\begin{abstract}
Background: The community pharmacist is a key player in medication reviews of older outpatients. However, it is not always clear which individuals require a medication review. The objective of the present study was to identify high-priority older patients for intervention by a community pharmacist.

Methods: As part of their final-year placement in a community pharmacy, pharmacy students conducted 10 interviews each with older adults (aged 65 or over) taking at least five medications daily. The student interviewer also offered to examine the patient's home medicine cabinet. An interview guide was developed by an expert group to assess the difficulties in managing and taking medications encountered by older patients.
\end{abstract}

Results: The 141 students interviewed a total of 1370 patients (mean age: 81.5; mean number of medications taken daily: 9.3). Of the 1370 interviews, 743 (54.2\%) were performed in the patient's home, and thus also included an examination of the home medicine cabinet. Adverse events were reported by 566 (42.0\%) patients. A total of 378 patients (27.6\%) reported difficulties in preparing, administering and/or swallowing medications. The inspections of medicine cabinets identified a variety of shortcomings: poorly located cabinets (in 15.0\% of inspections), medication storage problems (21.7\%), expired medications (40.7\%), potentially inappropriate medications (15.0\%), several different generic versions of the same drug (19.9\%), and redundant medications (20.4\%).

Conclusions: In a community pharmacy setting, high-priority older patients for intervention by a community pharmacist can be identified by asking simple questions about difficulties in managing, administering, taking or storing medications.

\section{Background}

Polypharmacy exposes older adults to an increased risk of adverse drug reactions [1-3], and has a significant impact on mortality and the likelihood of hospitalization $[4,5]$. Several interventions aimed at reducing this risk have been suggested, with a notable focus on detecting and reducing potentially inappropriate prescriptions [6]. These interventions require healthcare professionals to be more aware of at-risk situations and patients requiring particular assistance. In France, the community

\footnotetext{
* Correspondence: jean-baptiste.beuscart@univ-lille2.fr

${ }^{1}$ University of Lille, EA 2694 - Santé publique: épidémiologie et qualité des soins, F-59000 Lille, France

${ }^{2}$ Department of Geriatrics, CHU Lille, F-59000 Lille, France

Full list of author information is available at the end of the article
}

pharmacist now has an increasingly important and changing role in care provision for patients with chronic diseases, and can even become a patient's designated pharmacist. This status enables the pharmacist to adapt the patient's treatment (in collaboration with the patient's family physician), notably on the basis of a medication review.

The Pharmaceutical Care Network Europe working group on medication review has defined the latter as " $a$ structured evaluation of a patient's medicines with the aim of optimizing medicines use and improving health outcomes. This entails detecting drug related problems and recommending interventions". A formal medication review includes several components: an assessment of

(c) The Author(s). 2019 Open Access This article is distributed under the terms of the Creative Commons Attribution 4.0 International License (http://creativecommons.org/licenses/by/4.0/), which permits unrestricted use, distribution, and reproduction in any medium, provided you give appropriate credit to the original author(s) and the source, provide a link to the Creative Commons license, and indicate if changes were made. The Creative Commons Public Domain Dedication waiver (http://creativecommons.org/publicdomain/zero/1.0/) applies to the data made available in this article, unless otherwise stated. 
treatment adherence and safety, the identification of any drug interactions, reminders about good administration practice, appropriate medication use, and feedback to the prescribing physician(s). Medication review is known to be associated with a decrease in the number of drug related problems and inappropriate prescription $[7,8]$. However, the other putative benefits of medication review's (in terms of less frequent hospitalizations and reduced mortality) are subject to debate $[9,10]$. Moreover, it is not always clear which individuals require a medication review. Several studies were conducted with the purpose of better identifying patients at risk of adverse drug events but their predictive value was low and few of them were conducted among older patients [11]. One can hardly determine which older patient should be prioritized for medication review.

Improved cross-disciplinary communication increases the success rate for this type of intervention $[12,13]$ but requires community pharmacists or pharmacy students to be trained accordingly [14, 15]. Faculties of pharmacy are now focusing on training students to perform these new duties. Specific teaching units are based on real-life scenarios and their application during an internship typically the community pharmacy internship for finalyear students. At the Lille Faculty of Pharmacy, the final-year internship always includes work related to the patient's care pathway [16]. In 2015, this work addressed good prescribing practice for older patients with polypharmacy.

The primary objective of the present study was to identify high-priority patients for medication review in a community pharmacy setting. To this end, we assessed the difficulties in managing and taking medications encountered by older patients.

\section{Methods}

\section{Study design}

This was a cross-sectional study performed between January 5th and June 30th, 2015, in community pharmacies in the Nord-Pas-de-Calais region of France. Each of the 141 sixth-year student interns was asked to interview 10 older patients (aged 65 and over) taking at least five medications daily, in order to assess their home medication management. This interview could be performed in the pharmacy or (if the patient agreed) at the patient's home. In the latter case, the interviewer examined the patient's home medicine cabinet and assessed medication storage.

\section{Ethical aspects}

The need for consent was waived by the local independent ethics committee (CPP Nord-Ouest IV, Lille, France), which decided that the study was non-interventional. People could oppose the collection of their data at the time of the interview or could ask the responsible of the data (Pr B. Decaudin) to remove their data from the data base at any time after the interview. Consequently, in line with French legislation, a formal approval was not required but there was a formal information, which gave the right to the people to access, modify or remove their data upon request. The study was registered with the French National Data Protection Commission (CNIL, Paris, France; reference: 1826665).

\section{Study preparation}

A working group (comprising faculty members, community pharmacists, family physicians, and geriatricians) drew up several standardized study documents: (i) an interview guide, (ii) guidance on interviewing and collecting information, and (iii) a letter for the patient's family physician. Moreover, community pharmacists in eight towns in the region attended seminars on good practice in drug use in older patients.

\section{Interviews and data collection}

The pharmacy students presented the project to the community pharmacy's staff, detected potential interviewees, sent a letter to the patient's family physician, made an appointment (in agreement with the patient and the supervising community pharmacist), and prepared and conducted the interview. Convenience sampling was used. If a patient was not able to come to the pharmacy, the patient's primary carer was invited for the interview. The data on the patient's medications were collected in a three-section interview grid: (i) information on the patient and his/her medications; (ii) the patient and/or carer's level of knowledge about the medications, and the level of adherence (on the questionnaire recommended by the French national health insurance [17]); and (iii) management of medications, with questions on whether the patient could prepare and/or administer medications on his/her own, and possible difficulties in preparing and administering medications. The questionnaire is provided in Additional file 1. Geriatric syndromes were assessed by simple questions. For each medicine, the patient's knowledge about indication was investigated. Familiarity with medicine was evaluated through the ratio between the number of wellidentified medicines to the total number of medicine of the patient.

If agreed to by the patient, the interview was performed at the patient's home. In that case, data were also collected on the patient's medicine cabinet (location and size) and the latter's contents (the number of out-of-date medications, redundant medications, the presence of several generic formulations of a drug with the same dose level, and the presence of potentially inappropriate and/or at-risk medications with regard to the patient's 
comorbidities and other treatments). Potential inappropriateness was assessed on the basis of both implicit and explicit criteria [18]. The questionnaire for medicine cabinet inspection is provided in Additional file 2.

\section{Statistical analysis}

Quantitative variables were quoted as the mean \pm standard deviation (SD) or (for non-normal distributions) the median [interquartile range (IQR)]. Qualitative variables were quoted as the number (percentage). Normal distribution was checked by graphical method (histogram and density curves).

One of the study's objectives was to identify factors associated with difficulties in preparing and taking medications. The dependent variable was "difficulty in preparing or taking medications", which corresponded to the aggregate replies to three questions in the study questionnaire (on difficulties in preparing, taking and/or swallowing medications). Firstly, a logistic bivariate regression was used to probe associations between the dependent variable and the other descriptive variables from the questionnaire. Variable with more than $10 \%$ of missing data were excluded from the analysis. This model generated a loglinear relationship between the dependent variable and the continuous variables. The log-linearity hypothesis was checked in a cubic spline approach, and was found to hold for the "age" variable (which was then fed into the model as a continuous variable).

Secondly, a multivariate logistic regression model was applied. Given that this was a pilot study with no prior knowledge of which variables should be selected first, all dependent variables with a $p$-value below 0.20 in the bivariate analysis were included in the multivariate analysis. The variables were then selected in a forward and then backward step-wise analysis. Multi-collinearity was checked by the measure of the variance inflation factor and The goodness-of-fit was assessed by the HosmerLemeshow test.

All statistical analyses were performed with $\mathrm{R}$ software (version 3.2.0) [19].

\section{Results}

\section{Characteristics of the study population}

The 141 students performed interviews with a total of 1370 patients, including $743(54.2 \%)$ who agreed to an assessment of the home medicine cabinet. The characteristics of the patients and their medications are summarized in Table 1. The mean \pm SD age was $81.5 \pm 5.7$. Nearly one in two of the patients (48.5\%) lived on their own, and $43.8 \%$ of the patients had a home help. Over half of the patient reported suffering from geriatric syndromes: $51.5 \%$ of the patients had already had a fall, $66.1 \%$ had problems walking, and $23.8 \%$ had lost weight in the previous 6 months. Moreover, $23.7 \%$ of the patients had been hospitalized in the previous 6 months.

\section{Treatment adherence, and knowledge about medications} The mean \pm SD number of medications taken daily was $9.3 \pm 3.2$. Self-medication was reported by 340 patients $(34.8 \%$; missing data $=392)$ taking a median $[\mathrm{IQR}]$ of $1[1$; $2]$ over-the-counter medications per day (maximum: 15). Adverse events were reported by 566 patients (42.0\%).

Most of the patients (81.3\%) said that they knew which medications they were taking. This statement was corroborated by the fact that the indication for at least $75 \%$ of their daily medicines was known to $61.7 \%$ of the patients. On the questionnaire recommended by the French national health insurance, $45.3 \%$ of the patients displayed good adherence, and $8.8 \%$ displayed poor adherence. The remaining patients presented minor adherence problems; many of the patients felt that they had too many pills to take each day, and therefore sometimes stopped taking their medication $(n=434(32.6 \%)$ replied "yes" to question 6 on the questionnaire recommended by the French national health insurance).

When preparing their medications, $64.2 \%$ of the patients referred to their prescription, and the remainder referred to the information written on the medication's packaging by the pharmacist. About one in two patients (53.5\%) owned a pill box. In total, 261 (19.1\%) interviews led to a discussion with the patient's family physician about particular points noted by the pharmacy student.

\section{Patients encountering difficulties}

After the fulfilment of their prescriptions at the community pharmacy, more than a quarter of the patients $(n=$ $378 ; 27.6 \%)$ reported difficulties at home with regard to medication preparation, administration and/or swallowing (Table 1). The results of the bivariate and multivariate analyses are summarized in Table 2. Variance inflation factor was lower than 1.5 for all covariates, suggesting the absence of multi-collinearity; the goodness-of-fit was satisfactory according to the Hosmer-Lemeshow test $(P=$ 0.6328). The multivariate analysis showed that older age, the presence of a home help, self-reported adherence problems, and the occurrence of adverse events were independently associated with a greater likelihood of difficulties in preparing and/or taking medication at home. In contrast, the lack of third party assistance when taking medication was a protective factor.

\section{Medicine cabinet inspections}

The pharmacy students performed 743 inspections of the patient's home medicine cabinet (Table 3). On average, the visit lasted $14 \pm 10.2 \mathrm{~min}$. In the majority of cases (76.5\%) there was only one home medicine cabinet. The medicine cabinets were variously located in the kitchen, 
Table 1 Characteristics of the study population

\begin{tabular}{|c|c|c|}
\hline & MD (\%) & Patients $(n=1370)$ \\
\hline Age, years $[$ mean $\pm S D]$ & 0.6 & $81.5 \pm 5.7$ \\
\hline Living alone at home $[n(\%)]$ & 0.9 & $659(48.5 \%)$ \\
\hline Home help [n(\%)] & 1.5 & $592(43.8 \%)$ \\
\hline Falls ( $\geq 1$ in the previous 12 months) [n(\%)] & 3.0 & $685(51.5 \%)$ \\
\hline Difficulty walking [n(\%)] & 45.7 & $492(66.1 \%)$ \\
\hline Recent weight loss [n(\%)] & 2.2 & $319(23.8 \%)$ \\
\hline Hospitalization in the previous 6 months [n(\%)] & 1.2 & $321(23.7 \%)$ \\
\hline Self-reported medical history & 3.1 & \\
\hline Dementia [n(\%)] & & $74(5.6 \%)$ \\
\hline Dyslipidemia [n(\%)] & & $652(49.1 \%)$ \\
\hline Diabetes [n(\%)] & & $445(33.5 \%)$ \\
\hline Heart failure [n(\%)] & & $320(24.1 \%)$ \\
\hline Myocardial infarction [n(\%)] & & $186(14.0 \%)$ \\
\hline LEAOD [n(\%)] & & $108(8.1 \%)$ \\
\hline Chronic kidney failure [n(\%)] & & $74(5.6 \%)$ \\
\hline Other $[n(\%)]$ & & $1034(77.9 \%)$ \\
\hline Number of medications taken daily [mean \pm SD] & 11.5 & $9.3 \pm 3.2$ \\
\hline Number of OTC medications taken daily [median (IQR)] & 28.6 & $0[0 ; 1]$ \\
\hline Self-reported adverse events [n(\%)] & 1.7 & $566(42.0 \%)$ \\
\hline Self-medication [n(\%)] & 1.6 & $426(31.6 \%)$ \\
\hline Knowledge of what the medications are for & 2.6 & $1084(81.3 \%)$ \\
\hline Familiarity with medications & 11.9 & \\
\hline Familiarity with < 25\% [n(\%) & & $108(8.9 \%)$ \\
\hline Familiarity with $25-50 \%$ [n(\%)] & & $102(8.5 \%)$ \\
\hline Familiarity with $50-75 \%$ [n(\%)] & & $187(15.5 \%)$ \\
\hline Familiarity with $\geq 75 \%$ [n(\%)] & & $810(67.1 \%)$ \\
\hline French health insurance adherence questionnaire & 2.0 & \\
\hline Good adherence [n(\%)] & & $608(45.3 \%)$ \\
\hline Minor adherence problems [n(\%)] & & $616(45.9 \%)$ \\
\hline Poor adherence $[\mathrm{n}(\%)]$ & & $118(8.8 \%)$ \\
\hline Difficulties in preparing or administering medications [n(\%)] & 0 & $378(27.6 \%)$ \\
\hline Difficulties in preparing [n(\%)] & 4.2 & $164(12.5 \%)$ \\
\hline Difficulties in administering $[\mathrm{n}(\%)]$ & 3.3 & $130(9.8 \%)$ \\
\hline Difficulties in swallowing [n(\%)] & 1.2 & $154(11.4 \%)$ \\
\hline
\end{tabular}

Abbreviations: MD Missing data, SD Standard deviation, LEAOD Lower extremity arterial occlusive disease, OTC Over-the-counter

living room, bathroom, and bedroom. In $15.0 \%$ of cases, the medicine cabinet was considered to be in an unsuitable location for various reasons, such as a room with high levels of humidity or a hard-to-reach place. More than a third of the patients shared their medicine cabinet: $30.4 \%$ shared with their spouse, and $6.0 \%$ shared with another person (usually their son or daughter).

In 152 cases (21.7\%), storage problems were noted. In most cases, these were related to medications lacking their packaging and information sheets. Expired medications were found in $40.7 \%$ of the medicine cabinets, and over $25 \%$ of the cabinets contained three or more expired medications. One medicine cabinet contain 66 expired medications, and other contained a medication that had expired in 1992 (23 years previously). Information about the regular use or not of expired medication was not collected. Furthermore, $24.7 \%$ of the patients were storing other products (e.g. veterinary medications, cosmetics, hygiene products and even foodstuffs) with their medications. 
Table 2 Bivariate and multivariate analysis of the factors associated with difficulty preparing or administering medications at home

\begin{tabular}{|c|c|c|c|c|}
\hline & \multicolumn{2}{|c|}{ Bivariate analysis } & \multicolumn{2}{|c|}{ Multivariate analysis } \\
\hline & OR & $95 \% \mathrm{Cl}$ & OR & $95 \% \mathrm{Cl}$ \\
\hline Age & 1.04 & $1.02-1.06$ & 1.03 & $1.00-1.05$ \\
\hline Living alone & 1.02 & $0.79-1.31$ & & \\
\hline Home help & 1.98 & $1.53-2.56$ & 1.59 & $1.20-2.09$ \\
\hline Dementia & 1.80 & $1.06-3.08$ & & \\
\hline Falls & 1.20 & $0.93-1.55$ & & \\
\hline Recent weight loss & 1.45 & $1.09-1.92$ & 1.25 & $0.93-1.69$ \\
\hline Hospitalization in the previous 6 months & 1.32 & $0.99-1.75$ & & \\
\hline Self-reported adverse events & 1.61 & $1.25-2.08$ & 1.50 & $1.15-1.96$ \\
\hline Medications prepared by the patient & 0.60 & $0.44-0.80$ & & \\
\hline Medications prepared with reference to the prescription & 0.90 & $0.69-1.17$ & & \\
\hline $\begin{array}{l}\text { Medications prepared with reference to the information } \\
\text { written on the box by the pharmacist }\end{array}$ & 1.13 & $0.88-1.46$ & & \\
\hline Use of a pill box & 1.24 & $0.96-1.60$ & & \\
\hline Medications administered by the patient & 0.41 & $0.28-0.61$ & 0.53 & $0.35-0.80$ \\
\hline Knowledge of the treatment & 0.58 & $0.43-0.78$ & 0.77 & $0.55-1.06$ \\
\hline \multicolumn{5}{|l|}{ French health insurance adherence questionnaire } \\
\hline Good adherence & 1 & & 1 & \\
\hline Minor adherence problems & & & 1.33 & $1.01-1.77$ \\
\hline Poor adherence & 3.15 & $2.04-4.86$ & 2.63 & $1.67-4.14$ \\
\hline
\end{tabular}

One or more potentially inappropriate and/or at-risk medications (with regard to a patient's comorbidities and treatments) were identified in $15.0 \%$ of the medicine cabinets. Several different generic formulations of a given drug at the same dose level were found in $19.0 \%$ of the medicine cabinets inspected. Moreover, redundant medications were evidenced in $20.4 \%$ of the medicine cabinets.

\section{Discussion}

The present study provided a particularly valuable description of older patients attending community pharmacies in the north of France, and their home medications. Our results revealed that more than a quarter of the patients had difficulty preparing or administering medications at home. A total of over 700 medicine cabinet inspections identified some problems related to poor location/storage and the frequent presence of inappropriate and redundant medications. Our identification of difficulties in home medication management opens up new opportunities for caring for older outpatients; the community pharmacist is particularly well placed to address these difficulties.

The patients included in the present study were representative of older people attending community pharmacies. On average, a patient was taking 9.3 prescription medications a day. This high number is similar to that found in a general-population survey of over 200,000 people living in the region of France where the present study was performed [20]. Furthermore, many of the older people in our study reported geriatric syndromes, such as falls, balance disorders and weight loss. These findings are suggestive of a high proportion of frail patients (estimated at $39-45 \%$ in people aged 85 and over [21]).

The patients had a satisfactory level knowledge of their medications, and $67 \%$ of the patients were familiar with at least $75 \%$ of their medications. These findings are similar to those recorded in other European countries $[22,23]$. A comparison of two studies performed in Denmark and Sweden suggested that knowledge of medications increased over time, since the proportion of patients familiar with at least $75 \%$ of their medications rose from $60 \%$ in 2000 to $71 \%$ in 2009 [22, 23]. Our study further showed that the older people overestimate their level of knowledge because $81.3 \%$ thought that they were familiar with all their medications. Barat et al.'s study also showed that only $4 \%$ of the 348 included older patients had been informed about the risk of adverse events [22]. In a Finnish study of older adults, only $11.4 \%$ of the 404 interviewees reported an adverse event [24]. Self-reported adverse events were more frequent in our study; $42 \%$ of the interviewees reported one or more event. However, the participants in the Danish and Finnish studies were taking fewer medications than the participants in our study, and a high number of 
Table 3 Characteristics and content of the home medicine cabinets inspected $(n=743)$

\begin{tabular}{|c|c|c|}
\hline & MD (\%) & Cabinets inspected $(n=743)$ \\
\hline A single home medicine cabinet & 0.5 & $565(76.5 \%)$ \\
\hline Unsuitable location & 6.6 & $104(15.0 \%)$ \\
\hline Location: & 26.0 & \\
\hline Kitchen & & $192(34.9 \%)$ \\
\hline Living room & & $146(25.6 \%)$ \\
\hline Bathroom & & $109(19.8 \%)$ \\
\hline Bedroom & & $54(9.8 \%)$ \\
\hline Other room & & $49(8.9 \%)$ \\
\hline Type of medicine cabinet: & 0.4 & \\
\hline Cupboard & & $406(54.9 \%)$ \\
\hline Bag & & $61(8.2 \%)$ \\
\hline Drawer & & $172(23.2 \%)$ \\
\hline Other & & $171(23.1 \%)$ \\
\hline Medicine cabinet used by: & 3.1 & \\
\hline The patient only & & $510(69.3 \%)$ \\
\hline The patient and his/her spouse & & $224(30.4 \%)$ \\
\hline The patient and another person & & $44(6.0 \%)$ \\
\hline Storage problems & 5.8 & $152(21.7 \%)$ \\
\hline Number of expired drugs: & 1.9 & \\
\hline 0 & & $432(59.3 \%)$ \\
\hline $1-5$ & & $201(27.6 \%)$ \\
\hline $6-10$ & & $48(6.6 \%)$ \\
\hline $11-15$ & & $19(2.6 \%)$ \\
\hline$\geq 16$ & & $29(4.0 \%)$ \\
\hline Storage of products other than drugs & 1.2 & $181(24.7 \%)$ \\
\hline Presence of potentially inappropriate and/or at-risk medications & 6.6 & $104(15.0 \%)$ \\
\hline Redundant medications & 3.1 & $147(20.4 \%)$ \\
\hline Different generic formulations of the same drug at the same dose level & 2.8 & $137(19.0 \%)$ \\
\hline Patient with medications kept in the refrigerator & 0.8 & $129(17.5 \%)$ \\
\hline Inappropriate storage in the refrigerator $(n=129)$ & 0.8 & $22(3.0 \%)$ \\
\hline
\end{tabular}

Abbreviation: MD Missing data

medications is a major risk factor for adverse drug reactions $[25,26]$. Several studies have highlighted the potential value of patient-led pharmacovigilance reporting of adverse events, as a complement to reporting by physicians $[27,28]$. Our results suggest that there is significant potential for improving pharmacovigilance reporting by older patients, and that community pharmacists could usefully contribute to this process.

One important finding in the present study was that over a quarter of older patients had difficulty taking their medications at home, i.e. after the physician has issued a prescription and the pharmacist had provided the medication and corresponding advice. Although difficulties encountered by older people when taking medication have rarely been studied, these problems have been linked to poor adherence [29-31] - as also found in the present study. Our multivariate analysis identified several other factors associated with these difficulties, such as the need for a home help or the self-reported adverse events. However, not all of these factors can be easily spotted in the community pharmacy. Our results suggest that asking older people a few simple questions is enough to identify patients with difficulties. Discussing medications with a patient and his/her family might enable the pharmacist to suggest appropriate solutions (such as the implementation of a medication schedule, changes in pharmaceutical formulations, or the use of a pill box, tablet cutter or an eye dropper bottle) or to discuss the possible value of home assistance with medication administration. Multidose drug dispensing can also 
help the patients - notably with regard to better treatment adherence [32].

Another strength of our study relate to the 743 home visits with an inspection of the medicine cabinet. Medication storage problems were very common; they varied from an inappropriate location to the presence of redundant, inappropriate and/or at-risk medications. Many of these problems could be resolved by a few simple recommendations on home medication management from the pharmacy students. Our present findings appear to be of value because there are few published data on older people's home medicine cabinets [33]. In a study of 86 older patients in Hong Kong, Lee et al. found that (i) $69.7 \%$ of the participants had at least one medication storage problem, and (ii) these problems were strongly correlated with poor adherence (odds ratio 10.3 (95\% confidence interval: 2.5-44.6); $P<0.001$ ) [33]. In Lee et al.'s study, intervention by a pharmacist often resolved the patient's storage problems [33].

Lastly, our results showed that it is possible to raise awareness and train tomorrow's pharmacists in these new roles via a structured, innovative adaptation of the mandatory, final-year internship in a community pharmacy.

Our study had a number of strengths, including the large sample size, the high proportion of frail patients, the use of standardized questionnaires, the large number of home medicine cabinets inspected, and performance of interviews by pharmacy students (who proved themselves to be well qualified for addressing these topics).

The study also had some limitations. The elderly participants were selected by the community pharmacist supervising the internship, and half of the patients were not available or refused an inspection of their home medicine cabinet. Our results might therefore reflect the characteristics of people who had a good opinion of healthcare professionals, and so the significance of some characteristics may have been over- or underestimated. Geriatric syndromes were assessed by simple questions and were not evaluated by dedicated tools. Prevalence of geriatric syndromes may therefore have been under- or over-estimated. Information about the regular use or not of expired medication was not available, nor if expired medications concerned regularly used medications. Consequently, the potential danger of expired medications stored in the medicine cabinets could not be estimated. Furthermore, the "difficulty in taking medication" parameter was determined on a post-hoc basis from prospectively collected data. However, difficulties in taking medication have rarely been studied, and the scale of the problem could not be anticipated when the study questionnaire was drafted. Consequently, there was no sample size calculation and associations identified in the multivariable analysis may be due to unmeasured cofounding factors. Another limitation relates to the fact that the short study period prevented us from assessing any improvements in home medication management after an interview with the patient's family physician (i.e. a discussion of points raised by the medication review). Lastly, the study was performed in a single region of France, and so our observations may be specific to the cultural setting and/or the French healthcare system.

\section{Conclusion}

Community pharmacists are well placed to ask simple questions that identify high-priory patients for pharmaceutical intervention and a medication review. In a context of polypharmacy, the often frail older people attending community pharmacies frequently have difficulty in managing, storing, preparing and administering their medications.

\section{Supplementary information}

Supplementary information accompanies this paper at https://doi.org/10. 1186/s12877-019-1276-y.

Additional file 1. Topic guide for the management of personal treatment and side-effects.

Additional file 2. Topic guide for the medicine cabinet inspection.

\section{Abbreviations}

IQR: Interquartile range; SD: Standard deviation

\section{Acknowledgments}

We thank all the participating pharmacy students for their excellent work and strong commitment. We also thank the community pharmacists who supervised the students during their final-year internships.

\section{Authors' contributions}

$J B B, S P, P W, J M L, N K, E B, D M, D C, F P$, and $B D$ designed the study. SP and BD acquired the data. PW, NK, EB, DM, CB, DC, BD ensured practical follow-up of the pharmacy students during their final-year placement in a community pharmacy. JBB, SP, and TB performed the statistical analysis. JBB, SP, SG, PW, $T B, J M L, N K, E B, D M, C B, D C, F P, B D$ interpreted results. JBB, SP, and BD drafted the manuscript. SG, PW, JML, NK, EB, CB, DC, and FP revised the manuscript for important intellectual content. JBB, SP, SG, PW, TB, JML, NK, $E B, D M, C B, D C, F P, B D$ gave final approval for publication.

Funding

There is no source of funding to declare.

Availability of data and materials

The data supporting the findings can be obtained on reasonable request to the corresponding author.

Ethics approval and consent to participate

The need for consent was waived by the local independent ethics committee (CPP Nord-Ouest IV, Lille, France), which decided that the study was non-interventional. People could oppose the collection of their data at the time of the interview or could ask the responsible of the data (Pr B. Decaudin) to remove their data from the data base at any time after the interview. Consequently, in line with French legislation, a formal approval was not required but there was a formal information, which gave the right to the people to access, modify or remove their data upon request. The study was registered with the French National Data Protection Commission (CNIL, Paris, France; reference: 1826665).

Consent for publication

Not applicable. 


\section{Competing interests}

The authors declare that they have no competing interests.

\section{Author details}

'University of Lille, EA 2694 - Santé publique: épidémiologie et qualité des soins, F-59000 Lille, France. ${ }^{2}$ Department of Geriatrics, CHU Lille, F-59000 Lille, France. ${ }^{3}$ Department of Pharmacy, CHU Lille, F-59000 Lille, France. ${ }^{4}$ Department of Pharmacology, CHU Lille, F-59000 Lille, France. ${ }^{5}$ Association des Conseillers et des Pharmaciens Agréés Maîtres de stage du Nord Pas de Calais, Lille, France. ${ }^{6}$ Department of Public Health, CHU Lille, F-59000 Lille, France. 'Department of General Practice, University of Lille, F-50045 Lille Cedex, France. ${ }^{8}$ University of Lille, EA 7365 - Groupe de recherche sur les injectables et les technologies associées, F-59000 Lille, France. ${ }^{9}$ University of Lille, EA 4483, Impacts de l'environnement chimique sur la santé humaine (IMPECS), F- 59000 Lille, France.

\section{Received: 29 August 2018 Accepted: 10 September 2019}

Published online: 21 October 2019

\section{References}

1. Frazier SC. Health outcomes and polypharmacy in elderly individuals: an integrated literature review. J Gerontol Nurs. 2005;31:4-11.

2. Jyrkkä J, Enlund H, Korhonen MJ, Sulkava R, Hartikainen S. Polypharmacy status as an indicator of mortality in an elderly population. Drugs Aging. 2009;26:1039-48

3. Calderón-Larrañaga A, Poblador-Plou B, González-Rubio F, Gimeno-Feliu LA, Abad-Díez JM, Prados-Torres A. Multimorbidity, polypharmacy, referrals, and adverse drug events: are we doing things well? Br J Gen Pract J R Coll Gen Pract. 2012;62:e821-6.

4. Stevens JA, Corso PS, Finkelstein EA, Miller TR. The costs of fatal and non-fatal falls among older adults. Inj Prev J Int Soc Child Adolesc Inj Prev. 2006;12:290-5.

5. Evans D, Pester J, Vera L, Jeanmonod D, Jeanmonod R. Elderly fall patients triaged to the trauma bay: age, injury patterns, and mortality risk. Am J Emerg Med. 2015;33:1635-8.

6. Spinewine A, Schmader KE, Barber N, Hughes C, Lapane KL, Swine C, et al. Appropriate prescribing in elderly people: how well can it be measured and optimised? Lancet. 2007;370:173-84

7. Cooper JA, Cadogan CA, Patterson SM, Kerse N, Bradley MC, Ryan C, et al. Interventions to improve the appropriate use of polypharmacy in older people: a Cochrane systematic review. BMJ Open. 2015;5:e009235.

8. Clyne B, Fitzgerald C, Quinlan A, Hardy C, Galvin R, Fahey T, et al. Interventions to address potentially inappropriate prescribing in community-dwelling older adults: a systematic review of randomized controlled trials. J Am Geriatr Soc. 2016;64:1210-22.

9. Holland R, Desborough J, Goodyer L, Hall S, Wright D, Loke YK. Does pharmacist-led medication review help to reduce hospital admissions and deaths in older people? A systematic review and meta-analysis. Br J Clin Pharmacol. 2008;65:303-16.

10. Gray SL, Hart LA, Perera S, Semla TP, Schmader KE, Hanlon JT. Meta-analysis of interventions to reduce adverse drug reactions in older adults. J Am Geriatr Soc. 2018;66:282-8.

11. Falconer N, Barras M, Cottrell N. Systematic review of predictive risk models for adverse drug events in hospitalized patients. Br I Clin Pharmacol. 2018.

12. Kaae S, Sørensen EW, Nørgaard LS. Exploring communications around medication review in community pharmacy. Int J Clin Pharm. 2011;33:529-36.

13. Roberts AS, Benrimoj SI, Chen TF, Williams KA, Aslani P. Practice change in community pharmacy: quantification of facilitators. Ann Pharmacother. 2008:42:861-8

14. Jones KM, Blumenthal DK, Burke JM, Condren M, Hansen R, HolidayGoodman $\mathrm{M}$, et al. Interprofessional education in introductory pharmacy practice experiences at US colleges and schools of pharmacy. Am J Pharm Educ. 2012;76:80.

15. Luetsch K, Rowett D. Interprofessional communication training: benefits to practicing pharmacists. Int J Clin Pharm. 2015;37:857-64.

16. Belaiche S, Mercier E, Cuny D, Kambia N, Wierre P, Bertoux É, et al. Community pharmacists' interventions to prevent and screen chronic kidney disease patients. Nephrol Ther. 2017;13:87-92.

17. Questionnaire-evaluation-observance_assurance-maladie.pdf. https://www. ameli.fr/sites/default/files/Documents/5396/document/questionnaireevaluation-observance_assurance-maladie.pdf. Accessed 20 Aug 2019.
18. Laroche M-L, Charmes J-P, Merle L. Potentially inappropriate medications in the elderly: a French consensus panel list. Eur J Clin Pharmacol. 2007;63:725-31.

19. R Foundation for Statistical Computing. R: a language and environment for statistical computing. Vienna: R Development Core Team; 2010. http://www. R-project.org/

20. Beuscart J-B, Dupont C, Defebvre M-M, Puisieux F. Potentially inappropriate medications (PIMs) and anticholinergic levels in the elderly: a population based study in a French region. Arch Gerontol Geriatr. 2014;59:630-5.

21. Song $X$, Mitnitski A, Rockwood K. Prevalence and 10-year outcomes of frailty in older adults in relation to deficit accumulation. J Am Geriatr Soc. 2010;58:681-7.

22. Barat I, Andreasen F, Damsgaard EM. Drug therapy in the elderly: what doctors believe and patients actually do. Br J Clin Pharmacol. 2001;51:615-22.

23. Modig S, Kristensson J, Troein M, Brorsson A, Midlöv P. Frail elderly patients' experiences of information on medication. A qualitative study. BMC Geriatr. 2012:12:46.

24. Lampela P, Hartikainen S, Sulkava R, Huupponen R. Adverse drug effects in elderly people -- a disparity between clinical examination and adverse effects self-reported by the patient. Eur J Clin Pharmacol. 2007;63:509-15.

25. Alhawassi TM, Krass I, Bajorek BV, Pont LG. A systematic review of the prevalence and risk factors for adverse drug reactions in the elderly in the acute care setting. Clin Interv Aging. 2014;9:2079-86.

26. Nguyen JK, Fouts MM, Kotabe SE, Lo E. Polypharmacy as a risk factor for adverse drug reactions in geriatric nursing home residents. Am J Geriatr Pharmacother. 2006;4:36-41.

27. Avery AJ, Anderson C, Bond CM, Fortnum H, Gifford A, Hannaford PC, et al. Evaluation of patient reporting of adverse drug reactions to the UK "yellow card scheme": literature review, descriptive and qualitative analyses, and questionnaire surveys. Health Technol Assess Winch Engl. 2011;15:1-234 iii-iv.

28. Inch J, Watson MC, Anakwe-Umeh S. Patient versus healthcare professional spontaneous adverse drug reaction reporting: a systematic review. Drug Saf. 2012;35:807-18.

29. Atkinson L, Gibson II, Andrews J. The difficulties of old people taking drugs. Age Ageing. 1977:6:144-50.

30. Shah RB, Desai SV, Gajjar BM, Shah AM. Factors responsible for noncompliance to drug therapy in the elderly and the impact of patient education on improving compliance. Drugs Ther Perspect. 2013;29:360-6.

31. Orwig D, Brandt N, Gruber-Baldini AL. Medication management assessment for older adults in the community. The Gerontologist. 2006;46:661-8.

32. Kwint H-F, Stolk G, Faber A, Gussekloo J, Bouvy ML. Medication adherence and knowledge of older patients with and without multidose drug dispensing. Age Ageing. 2013;42:620-6.

33. Lee WWY, Pang KKW, Hui KC, Kwok JCK, Leung SL, Yu DSF, et al. Medication adherence: is it a hidden drug-related problem in hidden elderly? Geriatr Gerontol Int. 2013;13:978-85.

\section{Publisher's Note}

Springer Nature remains neutral with regard to jurisdictional claims in published maps and institutional affiliations.

Ready to submit your research? Choose BMC and benefit from:

- fast, convenient online submission

- thorough peer review by experienced researchers in your field

- rapid publication on acceptance

- support for research data, including large and complex data types

- gold Open Access which fosters wider collaboration and increased citations

- maximum visibility for your research: over $100 \mathrm{M}$ website views per year

At BMC, research is always in progress.

Learn more biomedcentral.com/submission 